\title{
The Functional Roles of the Cis-acting Elements in Bamboo mosaic virus RNA Genome
}

\author{
I-Hsuan Chen, Ying-Wen Huang and Ching-Hsiu Tsai* \\ Graduate Institute of Biotechnology, National Chung Hsing University, Taichung, Taiwan
}

Bamboo mosaic virus (BaMV), which belongs to the genus Potexvirus in the family Alphaflexiviridae, has a single-stranded positive-sense RNA genome that is approximately 6400 nucleotides (nts) in length. Positive-sense RNA viruses can use genomic RNA as a template for translation and replication after entering a suitable host cell. Furthermore, such viral RNA is recognized by capsid protein for packaging and by viral movement protein(s) or the movement protein complex for cell-to-cell and systemic movement. Hence, viral RNA must contain signals for different functions to complete the viral infection cycle. In this review, we examine various cis-acting elements in the genome of BaMV. The highly structured $3^{\prime}$ untranslated region (UTR) of the BaMV genomic RNA

OPEN ACCESS

Edited by:

K. Andrew White,

York University, Canada

Reviewed by:

Anne Elizabeth Simon University of Maryland, College Park,

USA

W. Allen Miller,

lowa State University, USA

*Correspondence:

Ching-Hsiu Tsai

chtsai1@dragon.nchu.edu.tw

Specialty section:

This article was submitted to

Virology,

a section of the journal

Frontiers in Microbiology

Received: 28 December 2016

Accepted: 29 March 2017

Published: 13 April 2017

Citation:

Chen I-H, Huang $Y-W$ and Tsai $C-H$

(2017) The Functional Roles of the

Cis-acting Elements in Bamboo

mosaic virus RNA Genome.

Front. Microbiol. 8:645.

doi: 10.3389/fmicb.2017.00645 plays multiple roles in the BaMV infection cycle, including targeting chloroplasts for RNA replication, providing an initiation site for the synthesis of minus-strand RNA, signaling for polyadenylation, and directing viral long-distance movement. The nt at the extreme $3^{\prime}$ end and the structure of the $3^{\prime}$-terminus of minus-strand RNA are involved in the initiation of plus-strand genomic RNA synthesis. Both these regions have been mapped and reported to interact with the viral-encoded RNA-dependent RNA polymerase. Moreover, the sequences upstream of open reading frames (ORFs) 2, 3, and 5 are involved in regulating subgenomic RNA synthesis. The cis-acting elements that were identified in BaMV RNA are discussed and compared with those of other potexviruses.

Keywords: positive-sense RNA virus, Bamboo mosaic virus, cis-acting elements, viral RNA replication, potexvirus

\section{INTRODUCTION}

For a positive-sense RNA virus to establish a successful infection in a host, the viral RNA must house diverse cis-acting elements for minus-strand, plus-strand, and possibly subgenomic RNA syntheses (Dreher, 1999; Newburn and White, 2015). Furthermore, cis-acting elements could also be involved in cell-to-cell or systemic movement and encapsidation of viral RNA (Kwon et al., 2005; Lough et al., 2006; Cho et al., 2012; Rossmann, 2013). Studying the mechanisms of viral infections, localizing these cis-acting elements, and revealing their functional structures are critical steps in understanding viral infections at the molecular level. A few approaches were used to determine the minimum length and structures of viral cis-acting elements required for various functions. An in vitro replication assay is one of the most frequently used strategies to define the minimal requirement of cis-acting RNA elements for replication (Lin et al., 2005a,b; Osman et al., 2014). However, the difficulty involved in isolating a competent replicase preparation that can synthesize minus- or plus-strand RNAs, specifically with the cis-acting elements provided, limits 
its use. The cis-acting elements discovered using this strategy were designated as promoters and are structured to specifically interact with the replicase. Structures of cis-acting elements have been computationally predicted and validated using enzymatic or chemical structural probing (Cheng and Tsai, 1999; Sun and Simon, 2006; McCormack et al., 2008). However, the structured cis-acting elements must be functionally verified by mutational analysis in either an in vitro replication assay or an in vivo infection assay.

Bamboo mosaic virus (BaMV) has a single-stranded positivesense RNA genome that is approximately $6.4 \mathrm{~kb}$ in length with a $5^{\prime}$-cap structure and a $3^{\prime}$ poly(A) tail. The genome contains five open reading frames (ORFs) (Figure 1). ORF1 encodes a replicase for viral RNA replication, ORF2 encodes a $28-\mathrm{kDa}$ protein (a silencing suppressor) required for viral movement, ORF3 and ORF4 encode membrane-anchoring proteins required for virus movement, and ORF5 encodes a $25-\mathrm{kDa}$ capsid protein for viral encapsidation, movement, and symptom development.

The cis-acting elements of BaMV RNA involved in viral RNA replication, intracellular trafficking, and movement have been extensively studied in the last two decades. This report comprehensively reviews these studies and discusses the common theme of the roles of these cis-acting elements that could be applied to other members of potexvirus including the Potato virus $X$ (PVX), one of the top 10 plant viruses in molecular plant pathology (Scholthof et al., 2011), and even to certain animal viruses of Alphaviruses.

\section{VIRAL RNA INTRACELLULAR TRAFFICKING}

When a positive-sense viral RNA enters a host cell, the host translation system is used to synthesize the viral proteins. The newly translated viral proteins target a specific membrane, usually an organelle-associated membrane, and modify the membrane suitable for viral RNA replication (Ahlquist et al., 2003; Laliberte and Sanfacon, 2010; Diaz et al., 2012; Nagy, 2016). The RNAs of Tobacco mosaic virus (Kawakami et al., 2004; Nishikiori et al., 2006), PVX (Bamunusinghe et al., 2009), Tomato ringspot virus (Han and Sanfacon, 2003), Cowpea mosaic virus (Carette et al., 2000), and Tobacco etch virus (Schaad et al., 1997) are transported to the endoplasmic reticulum membranes. The RNA of Tomato bushy stunt virus is transported to the peroxisomes (McCartney et al., 2005). The RNA of Melon necrotic spot carmovirus is associated with the mitochondria (Mochizuki et al., 2009). The RNAs of Turnip yellow mosaic virus (Prod'homme et al., 2003) and Turnip mosaic virus (Wei et al., 2010) are transported to the chloroplast membranes. These observations indicate that different viruses associate with distinct organellar membranes for replication (Laliberte and Sanfacon, 2010).

The mechanisms underlying the specific trafficking of viral RNA to targeted organelles for replication remain less known. In a recent study, BaMV was demonstrated to associate with chloroplasts for replication (Cheng et al., 2013). When the interaction between the $3^{\prime}$ untranslated region (UTR) of BaMV
RNA (Figure 1) and host proteins in the replicase complex was studied, the involvement of elongation factor 1a (eEF1a) and chloroplast phosphoglycerate kinase (PGK) was revealed (Lin et al., 2007). A further study of the interactions indicated that a pseudoknot, including the poly(A) sequence at the extreme $3^{\prime}$ end, is the target of PGK. In vitro and in vivo studies revealed that the interaction is required for efficient replication (Lin et al., 2007; Cheng et al., 2013). Notably, the chloroplast PGK can be replaced by a chimeric protein composed of cytoplasmic eEF1a and chloroplast RuBisCo small subunit (rbcS) (Cheng et al., 2013). These results suggest that nuclear-encoded chloroplast proteins, such as PGK and rbcS may serve to transport chloroplast-unrelated macromolecules into the chloroplasts by using their transit peptide. Once inside the host cell, the $3^{\prime}$-terminal pseudoknot and poly(A) sequence of BaMV RNA interact with PGK. The chloroplast PGK transit peptide facilitates entry into the chloroplast transport system. PGK and its associated macromolecules (BaMV RNA and possibly the translated replicase or the entire replicase complex) are transported into the chloroplasts (Cheng et al., 2013).

\section{MINUS-STRAND RNA SYNTHESIS}

During initiation of minus-strand RNA synthesis, cis-acting elements located at the $3^{\prime}$ end (usually in the $3^{\prime}$ UTR) in most viruses play a critical role in recognition by the replicase complex. Typically, the $3^{\prime}$-terminal nucleotides (nt) or penultimate nt of non-poly(A)-tailed RNA viruses is used as the initiation site for minus-strand RNA synthesis (Dreher, 1999, 2009). However, the poly(A)-tailed RNA viruses have RNA genomes containing approximately 250 adenylates at the $3^{\prime}$ end in the case of BaMV (Chen et al., 2005). Thus, cis-acting elements in the $3^{\prime}$ UTR are far from the extreme $3^{\prime}$ end of the initiation site if poly(A)-tailed viruses use a similar synthesis mechanism as described for non-poly(A)-tailed RNA viruses. Therefore, poly(A)-tailed RNA viruses might have a different strategy or use initiation sites that are close to the cis-acting elements. In vitro and in vivo studies of BaMV revealed that the extreme $5^{\prime}$ end of minus-strand RNA contains stretch of uridine residues ranging from 1 to $15 \mathrm{nt}$, usually about 7-10 uridines (Cheng et al., 2002). These results indicate that the replicase complex assembles on the cis-acting elements in the $3^{\prime}$ UTR, and that synthesis of minus-strand RNA initiates with uridylate. The consequence of minus-strand RNA synthesis is that the subsequently synthesized plus-strand genomic RNA would have only a short stretch of adenylates at the extreme $3^{\prime}$ end $(<15$ nts in length).

Cis-acting elements for minus-strand RNA synthesis, as mentioned previously, are usually situated in the $3^{\prime}$ UTR and form secondary or tertiary structures, such as the stem-loops of Alfalfa mosaic virus (Houser-Scott et al., 1994; Reusken and Bol, 1996; Houser-Scott et al., 1997) and Turnip crinkle virus (Song and Simon, 1995) and the tRNA-like structures of Brome mosaic virus, Tobacco mosaic virus, and Turnip yellow mosaic virus (Kao and Sun, 1996; Osman and Buck, 1996; Deiman et al., 1997, 1998; Singh and Dreher, 1997). 


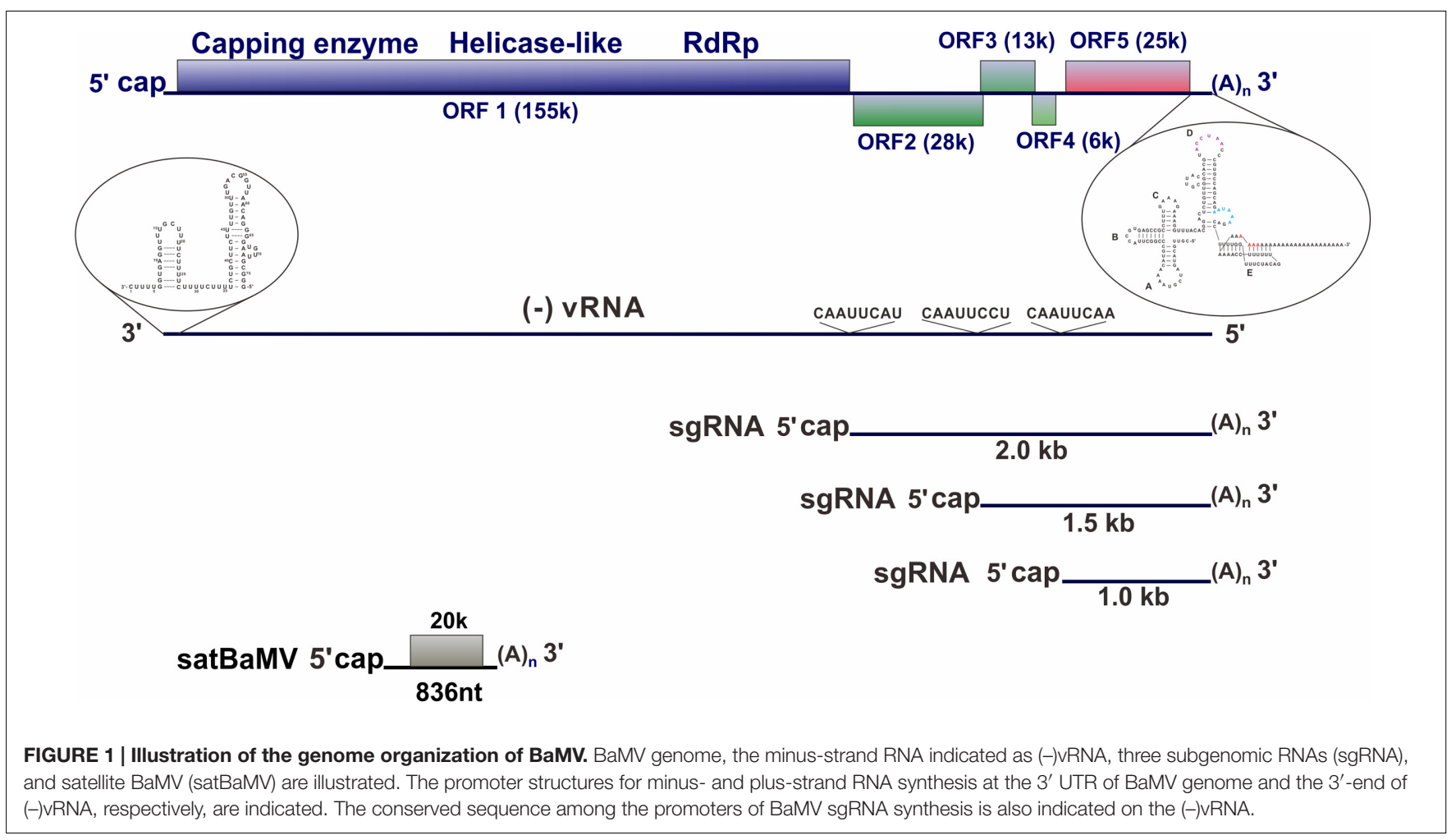

The cis-acting elements for BaMV minus-strand RNA synthesis were also identified in the $3^{\prime}$ UTR. The $3^{\prime}$ UTR can be divided into three portions: the $5^{\prime}$ part consisting of three stem-loops that form a cloverleaf-like structure, designated as the $\mathrm{ABC}$ domain; the middle part following the $\mathrm{ABC}$ domain, which is a major stem-loop with a bulge and an internal loop, designated as the D domain; and the $3^{\prime}$ part of the UTR that forms the pseudoknot, described previously that interacts with eEF1a and PGK, covering a part of the poly(A) sequence adjoining the $3^{\prime}$ UTR, designated as the E domain (Figure 2). Furthermore, results derived from ultraviolet (UV)-crosslinking and footprinting assays indicate that the polymerase and helicase-like domains of the replicase (ORF1 of BaMV) interact with the D and $\mathrm{E}$ domains and $\mathrm{ABC}$ domain of the $3^{\prime} \mathrm{UTR}$, respectively. The potexviral conserved hexamer motif (ACXUAA) involved in the accumulation of virus was discovered in Clover yellow mosaic virus (White et al., 1992) and BaMV (Cheng and Tsai, 1999). This motif is located at the apical loop of the D domain in the $3^{\prime}$ UTR of BaMV (Figure 2), and was protected from RNase digestion during interaction with the polymerase (Huang et al., 2001). The results of mutagenesis of this motif (ACCUAA in BaMV) indicate that the extreme $5^{\prime}$ adenylate is a purine-specific nt, and the subsequent $n t$ is by necessity a pyrimidine. The last three residues (UAA) are unalterable. The third nt affects viral accumulation less than the first two (Chiu et al., 2002).

Maintaining the structures of $\mathrm{D}$ and $\mathrm{E}$ domains is critical for efficient viral RNA replication (Tsai et al., 1999). Mutations that disrupt the stems resulted in inefficient accumulation of viral RNAs. When compensatory mutations were introduced to re-form the stems, viral replication was restored. Furthermore, retaining the pseudoknot structure of the $\mathrm{E}$ domain required 15 adenylates downstream (Cheng and Tsai, 1999). Viral full-length transcripts with $<10$ adenylates could not replicate sufficiently to be detected in the protoplasts. Transcripts with 15 adenylates at the $3^{\prime}$ end could accumulate only up to $26 \%$ of the amount of wild-type transcripts with 25 adenylates (Tsai et al., 1999). These results suggest that the polymerase domain of the BaMV replicase interacts with stem-loop D specifically with the hexamer motif (ACCUAA) and the pseudoknot for initiation of minus-strand RNA synthesis. The initiation site for the minus-strand RNA synthesis in BaMV is not fixed at one position, but initiation starts at one of the 15 adenylates adjoining the $3^{\prime}$ UTR (Cheng et al., 2002).

The stem-loops $\mathrm{B}$ and $\mathrm{C}$ of the $\mathrm{ABC}$ domain in the $3^{\prime}$ UTR play a lesser, but significant, role in RNA replication (Chen et al., 2003). Accumulation of viral RNA in mutants with deleted stem-loop B or C was approximately $30 \%$ of wild type. Notably, accumulation of viral products of mutants with deleted stem-loop A did not differ significantly from that of wild type in protoplasts and inoculated leaves, but accumulation decreased dramatically in systemic leaves. These results suggest that stem-loop A is a cis-acting element for long-distance movement and does not play a role in RNA replication (Figure 2).

\section{PLUS-STRAND RNA SYNTHESIS}

In an in vitro transcription assay, short transcripts of 39,77 , and $173 \mathrm{nts}$ in length, corresponding to the $3^{\prime}$ terminus of minusstrand RNAs, were used as templates to examine their ability 


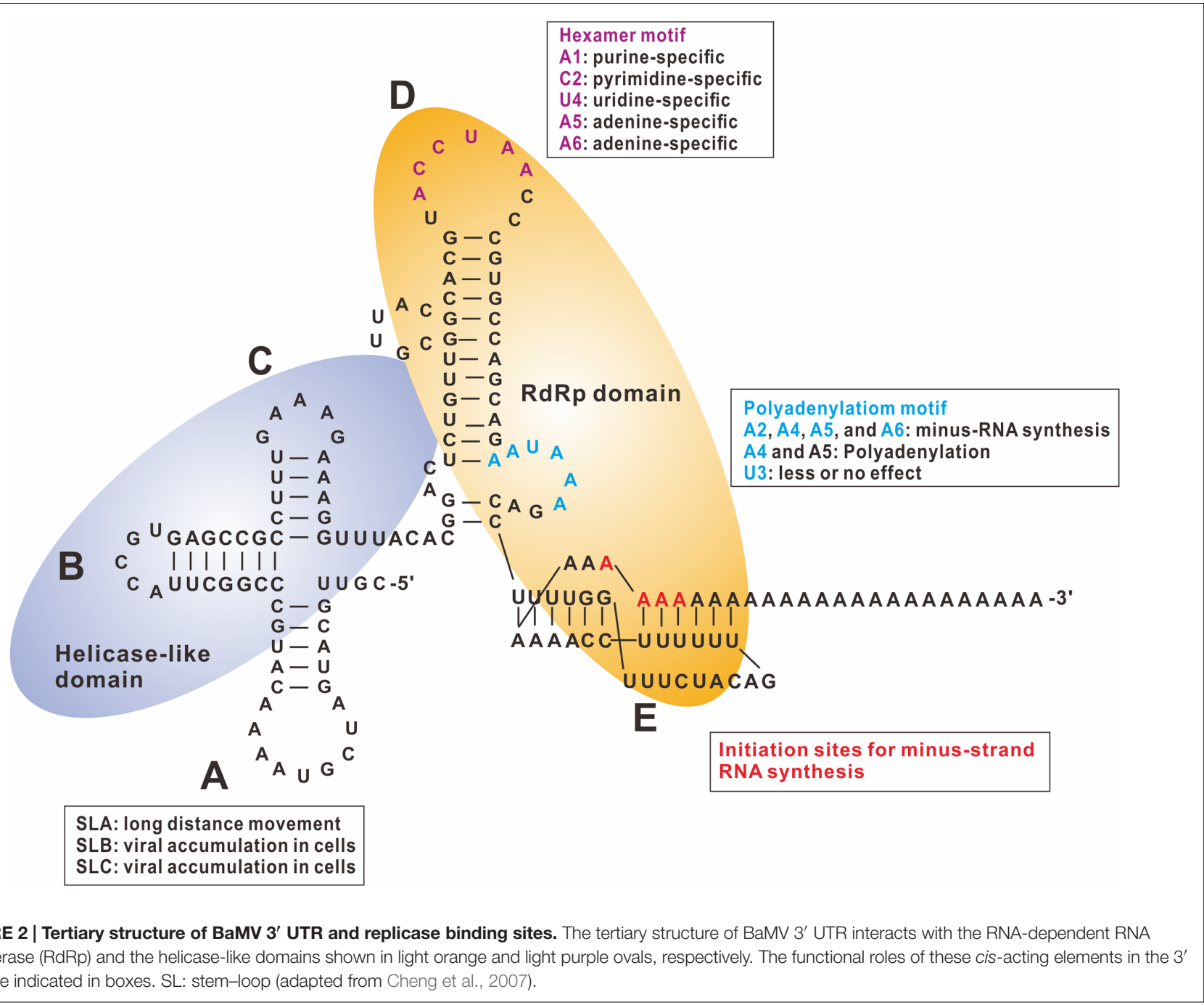

to direct RNA synthesis. The 3'-terminal 77-nt RNA, designated Ba-77, was the most efficient RNA template (Figure 3). It harbors two complete stem-loops confirmed by enzymatic structural probing and is required for plus-strand RNA synthesis (Lin et al., 2005a).

The terminal UUUUC pentamer is the most critical cis-acting element in BaMV for plus-strand RNA synthesis. Ba-77/ $\Delta 5$, which lacks the terminal pentamer, exhibited only $7 \%$ template activity compared with that of Ba-77 in vitro. Ba-77 with an internal deletion of 16 or 31 nts (starting after the terminal pentamer) (Figure 3) and retaining the terminal UUUUC preserves up to $60 \%$ of the template activity of Ba-77 (Lin et al., 2005a). Furthermore, the sequence and structure of the large stem-loop at the extreme $5^{\prime}$ end of $\mathrm{Ba}-77$ are also vital for RNA synthesis. In mutants with altered sequences of the large stem-loop, RNA synthesis in vitro and viral RNA accumulation in vivo decreased significantly. Moreover, the sequence between the terminal pentamer initiation site and the large stem-loop may also play a significant role as mutants with shortening the sequence between the terminal UUUUC and the stem-loop exhibited decreased accumulation of BaMV RNA in vivo and plus-strand RNA synthesis in vitro (Lin et al., 2005a).

At least three cis-acting elements at the $3^{\prime}$ end of BaMV minus-strand RNA are required for efficient plus-strand genomic RNA synthesis, namely the $3^{\prime}$-terminal UUUUC pentamer motif, the sequence and structure of the large stem-loop, and the distance between these two regions. Accordingly, these cis-acting elements constitute the promoter for genomic RNA synthesis. The replicase contains two domains that interact with the promoter: the replicase catalytic center interacts with the terminal UUUUC sequence, and the specificity domain interacts with the large stem-loop (Figure 3) (Chen et al., 2010).

As mentioned previously, the extreme $5^{\prime}$ end of minus-strand RNA has a short run of uridylates, copying from the poly(A) tail; therefore, the extreme $3^{\prime}$ end of plus-strand RNA immediately after synthesis accordingly has a short run of adenylates (most frequently 7-10). However, to maintain the approximately 250 adenylates at the extreme $3^{\prime}$ end of genomic RNA after synthesis, the cis-acting element AAUAAA in the $3^{\prime}$ UTR plays a role 


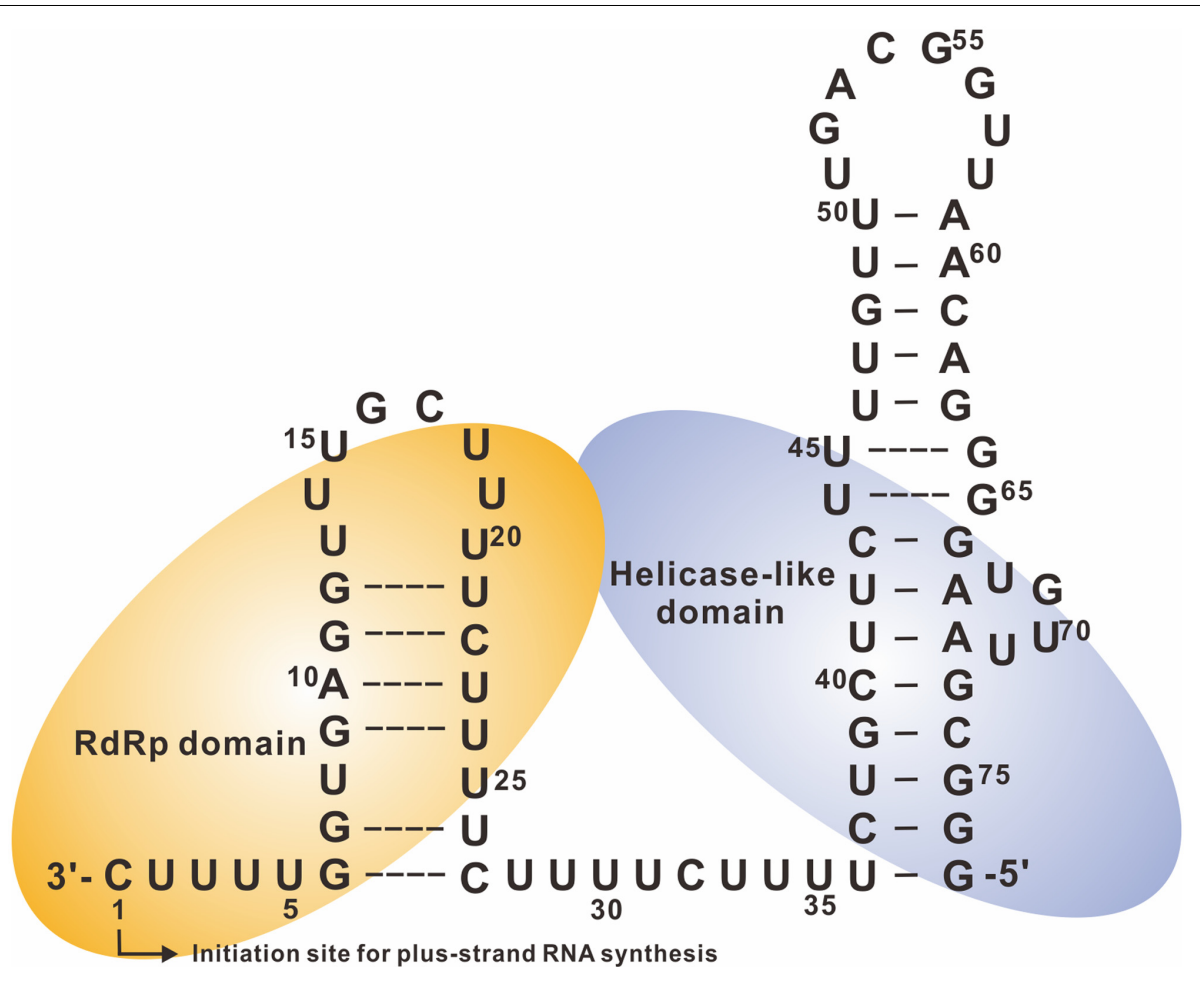

FIGURE 3 | Secondary structure of the $\mathbf{3}^{\prime}$-terminal $\mathbf{7 7}$ nts of BaMV minus-strand RNA and replicase binding sites. The secondary structure of the cis-acting elements for genomic RNA synthesis interacts with the polymerase (RdRp) and helicase-like domains shown in light orange and light purple, respectively. The broken lines between base-pairing indicate that this region could be unstructured or has potentially unstable according to the probing results. The initiation site is numbered +1 for plus-strand RNA synthesis (adpated from Cheng et al., 2007).

in polyadenylation (Chen et al., 2005). Interestingly, the cisacting element for polyadenlyation of BaMV RNA is identical to that of nuclear-encoded mRNAs. Whether BaMV uses an identical set of proteins as do nuclear-encoded host mRNAs for polyadenylation is an interesting question. A few observations oppose the aforementioned hypothesis on the use of identical proteins for polyadenylation. The host poly $(\mathrm{A})$ polymerase is located mainly in the nucleus. Furthermore, the polyadenylation of mRNAs with poly(A) polymerase is independent of the recognition of the AAUAAA motif, whereas the polyadenylation of BaMV is associated with the AAUAAA motif (Chen et al., 2005).

\section{SUBGENOMIC RNA SYNTHESIS}

The genomes of many positive-sense RNA viruses are multicistronic organizations that produce subgenomic RNAs (sgRNAs) to serve as messengers, allowing the translation of downstream ORFs (Sztuba-Solinska et al., 2011). A few strategies for synthesizing sgRNAs have been demonstrated, including internal initiation (Miller et al., 1985; Haasnoot et al., 2000), premature termination (White, 2002; Jiwan and White, 2011), and discontinuous synthesis (Sawicki and Sawicki, 1998; Pasternak et al., 2001). A short non-coding RNA derived from genomic RNA generated by host exonuclease is another strategy to synthesize subgenomic RNA (Iwakawa et al., 2008). They commonly rely on cis-acting RNA elements to direct the viral-encoded RdRp to transcribe these RNAs (Newburn and White, 2015).

BaMV infection produces three sgRNAs with $3^{\prime}$ cotermini. Two major sgRNAs of approximately 2 and $1 \mathrm{~kb}$ in length direct translation of ORF2 and ORF5, respectively (Lin et al., 1992). The other sgRNA, responsible for the translation of ORF3 and ORF4, is $1.5 \mathrm{~kb}$ in length accumulates in infected cells at a very low level. The satellite RNA of BaMV (satBaMV) was previously designed to be an expression cassette for examining cis-acting elements required for sgRNA synthesis (Lee et al., 2000). A cDNA covering the putative promoter region of BaMV sgRNA (SGP) was inserted into this cassette and resulted in sgRNA promoterdirected RNA synthesis in infected cells when coinoculated with BaMV. The cis-acting element of the SGP for synthesis of the $1-\mathrm{kb}$ sgRNA covers the region between $\mathrm{nt}-91$ to +52 (the transcription start site is designated as +1 ). Further analysis indicated that the SGP can be split into four elements: the core (nt -30 to +16 ), two upstream enhancers (nt -59 to -31 and -91 to -60$)$, and a downstream enhancer ( $\mathrm{nt}+17$ to +52 ). The core sequence is the minimum region required for $1-\mathrm{kb}$ sgRNA synthesis, which folds into two stem-loops, stem-loop (SL)1 and SL2, in minus strand (Figure 4A). Maintaining the integrity of SL2 structure and the conserved octamer motif $\left(3^{\prime}\right.$-CAAUUCAA- $\left.5^{\prime}\right)$ in the loop are essential for $1-\mathrm{kb}$ sgRNA 


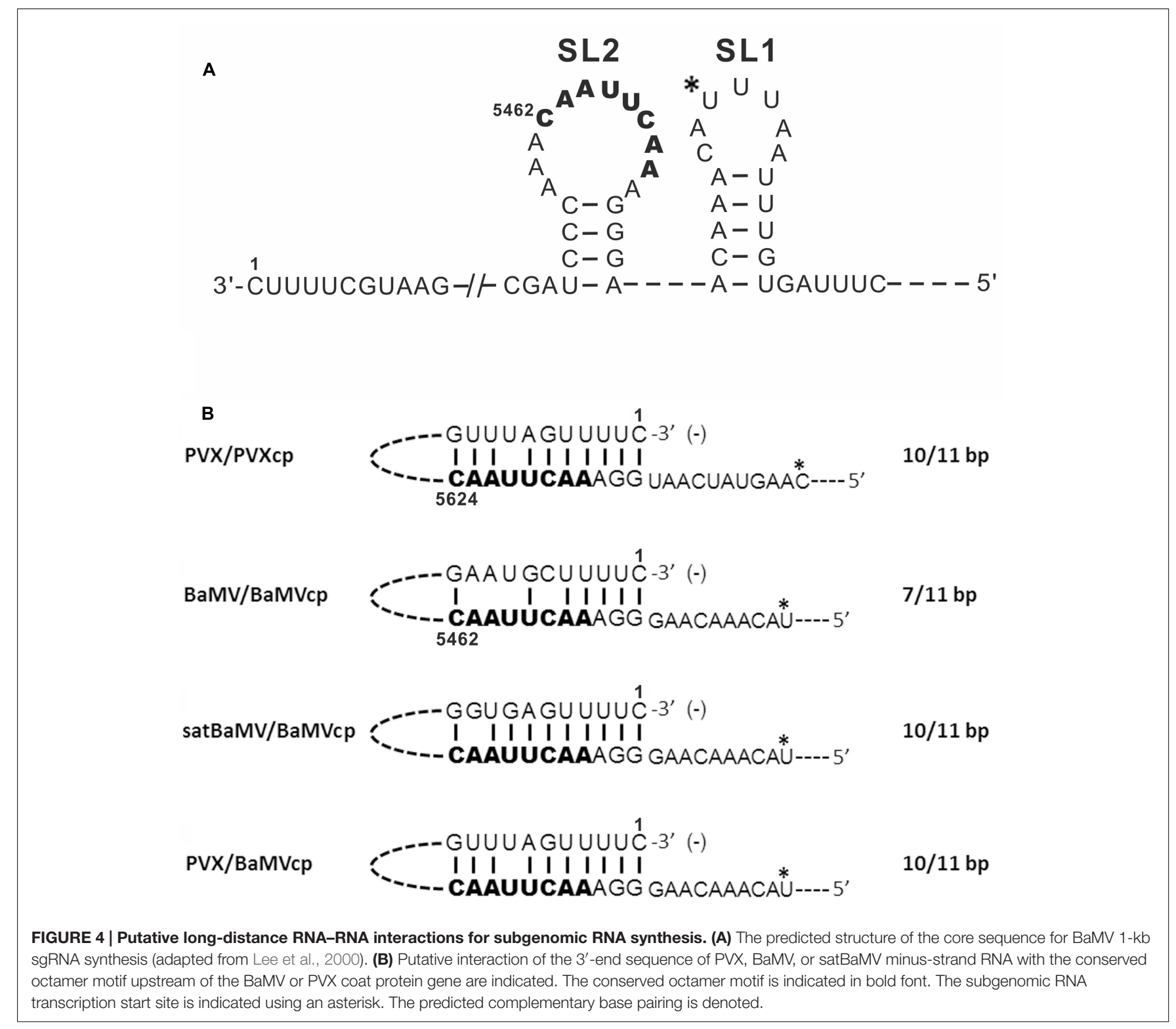

synthesis. Furthermore, the cis-acting elements of SGP for 2-kb sgRNA synthesis are located at $\mathrm{nt}-119$ to +11 (the transcription start site of the $2-\mathrm{kb}$ sgRNA is designated as +1 ). The minusstrand SGP sequence for 2-kb sgRNA synthesis was predicted to have similar stem-loops to those of the 1-kb SGP. The conserved octamer motif $\left(3^{\prime}\right.$-CAAUUCAU-5') is also located in the loop of SL2 (Lee et al., 2000). Furthermore, the expected octamer motif $\left(3^{\prime}\right.$-CAAUUCCU-5') for BaMV 1.5-kb sgRNA is located 12-nt upstream of the transcription start site.

Compared with the putative SGPs of ORF2 and ORF5 of potexviruses, the octamer motif is highly conserved (Kim and Hemenway, 1997; Lee et al., 1998). The long-distance RNA-RNA interaction between the conserved octamer motif and the 3 -terminal sequence of minus-strand genomic RNA was demonstrated to be required for transcription of PVX sgRNAs (Figure 4B) (Kim and Hemenway, 1999). As in an ortholog, a similar interaction was revealed in BaMV with shorter complementary pairing than those in PVX (Figure 4B). Although BaMV SGPs were inserted into the satBaMV cassette without a BaMV minus-strand $3^{\prime}$-terminal sequence, the octamer motif could also interact with the $3^{\prime}$-terminal sequence of minusstrand satBaMV RNA (Figure 4B) (Lee et al., 2000). Redundant SGPs in a PVX-based expression vector were found to lead to genetic instability. The heterologous SGP from BaMV used in the PVX vector improves its stability for long-term production of proteins (Dickmeis et al., 2014). Complementarity between the octamer motif from the BaMV SGP and the $3^{\prime}$-terminal sequence of the minus-strand genomic RNA is required for transcription of sgRNA synthesis (Figure 4B). The long-distance RNA-RNA interaction between of the $3^{\prime}$-terminal sequence and the conserved octamer motif of the SGPs observed in PVX and BaMV favors the internal initiation mode of sgRNA synthesis. 


\section{CONCLUDING REMARKS AND FUTURE PROSPECTIVES}

For accomplishing an efficient infection by a positive-sense RNA virus, the viral genome consists of various cis-acting elements for intracellular trafficking to organellar membranous target sites, minus-strand RNA synthesis, plus-strand genomic RNA synthesis, subgenomic RNA synthesis, viral movements, and viral encapsidation. In this review, we summarize studies of most of the cis-acting elements identified in the BaMV genome, except for those involved in viral movement and viral encapsidation. The signal for BaMV genomic RNA encapsidation is very likely in the $5^{\prime} \mathrm{UTR}$, similar to those identified in PVX (Kwon et al., 2005; Karpova et al., 2006; Petrova et al., 2013, 2015). The structural elements and the functional roles for

\section{REFERENCES}

Ahlquist, P., Noueiry, A. O., Lee, W. M., Kushner, D. B., and Dye, B. T. (2003). Host factors in positive-strand RNA virus genome replication. J. Virol. 77, 8181-8186. doi: 10.1128/JVI.77.15.8181-8186.2003

Bamunusinghe, D., Hemenway, C. L., Nelson, R. S., Sanderfoot, A. A., Ye, C. M., Silva, M. A., et al. (2009). Analysis of Potato virus $X$ replicase and TGBp3 subcellular locations. Virology 393, 272-285. doi: 10.1016/j.virol.2009.08.002

Carette, J. E., Stuiver, M., Van Lent, J., Wellink, J., and Van Kammen, A. (2000). Cowpea mosaic virus infection induces a massive proliferation of endoplasmic reticulum but not Golgi membranes and is dependent on de novo membrane synthesis. J. Virol. 74, 6556-6563. doi: 10.1128/JVI.74.14.6556-6563.2000

Chen, I. H., Chou, W. J., Lee, P. Y., Hsu, Y. H., and Tsai, C. H. (2005). The AAUAAA motif of Bamboo mosaic virus RNA is involved in minus-strand RNA synthesis and plus-strand RNA polyadenylation. J. Virol. 79, 14555-14561. doi: 10.1128/JVI.79.23.14555-14561.2005

Chen, I. H., Lin, J. W., Chen, Y. J., Wang, Z. C., Liang, L. F., Meng, M., et al. (2010). The 3 '-terminal sequence of Bamboo mosaic virus minus-strand RNA interacts with RNA-dependent RNA polymerase and initiates plus-strand RNA synthesis. Mol. Plant Pathol. 11, 203-212. doi: 10.1111/j.1364-3703.2009.00597.x

Chen, I. H., Meng, M., Hsu, Y. H., and Tsai, C. H. (2003). Functional analysis of the cloverleaf-like structure in the $3^{\prime}$ untranslated region of Bamboo mosaic potexvirus RNA revealed dual roles in viral RNA replication and long distance movement. Virology 315, 415-424. doi: 10.1016/S0042-6822(03)00560-9

Cheng, C. P., and Tsai, C. H. (1999). Structural and functional analysis of the $3^{\prime}$ untranslated region of Bamboo mosaic potexvirus genomic RNA. J. Mol. Biol. 288, 555-565. doi: 10.1006/jmbi.1999.2716

Cheng, J. H., Peng, C. W., Hsu, Y. H., and Tsai, C. H. (2002). The synthesis of minus-strand RNA of Bamboo mosaic potexvirus initiates from multiple sites within the poly(A) tail. J. Virol. 76, 6114-6120. doi: 10.1128/JVI.76.12.61146120.2002

Cheng, S. F., Huang, Y. P., Chen, L. H., Hsu, Y. H., and Tsai, C. H. (2013). Chloroplast phosphoglycerate kinase is involved in the targeting of Bamboo mosaic virus to chloroplasts in Nicotiana benthamiana plants. Plant Physiol. 163, 1598-1608. doi: 10.1104/pp.113.229666

Cheng, S. F., Lin, J. W., Chen, I. H., Hsu, Y. H., and Tsai, C. H. (2007). The identification of cis-and trans-acting elements in the infection cycle of Bamboo mosaic virus. Plant Viruses 1, 163-169.

Chiu, W. W., Hsu, Y. H., and Tsai, C. H. (2002). Specificity analysis of the conserved hexanucleotides for the replication of Bamboo mosaic potexvirus RNA. Virus Res. 83, 159-167. doi: 10.1016/S0168-1702(01)00433-6

Cho, S. Y., Cho, W. K., Choi, H. S., and Kim, K. H. (2012). Cis-acting element (SL1) of Potato virus $X$ controls viral movement by interacting with the NbMPB2Cb and viral proteins. Virology 427, 166-176. doi: 10.1016/j.virol.2012. 02.005

Deiman, B. A., Koenen, A. K., Verlaan, P. W., and Pleij, C. W. (1998). Minimal template requirements for initiation of minus-strand synthesis in vitro by the the encapsidation of BaMV RNA will be revealed in the near future.

\section{AUTHOR CONTRIBUTIONS}

I-HC wrote the section on the plus-strand RNA synthesis. Y-WH wrote the section of subgenomic RNA synthesis. C-HT wrote the rest part of the manuscript.

\section{ACKNOWLEDGMENT}

This work is supported by grant MOST 105-2311-B-005-002 from the Ministry of Science and Technology, Taiwan.
RNA-dependent RNA polymerase of Turnip yellow mosaic virus. J. Virol. 72, 3965-3972.

Deiman, B. A., Kortlever, R. M., and Pleij, C. W. (1997). The role of the pseudoknot at the $3^{\prime}$ end of Turnip yellow mosaic virus RNA in minus-strand synthesis by the viral RNA-dependent RNA polymerase. J. Virol. 71, 5990-5996.

Diaz, A., Gallei, A., and Ahlquist, P. (2012). Bromovirus RNA replication compartment formation requires concerted action of 1a's self-interacting RNA capping and helicase domains. J. Virol. 86, 821-834. doi: 10.1128/JVI. 05684-11

Dickmeis, C., Fischer, R., and Commandeur, U. (2014). Potato virus X-based expression vectors are stabilized for long-term production of proteins and larger inserts. Biotechnol. J. 9, 1369-1379. doi: 10.1002/biot.201400347

Dreher, T. W. (1999). Functions of the $3^{\prime}$-untranslated regions of positive strand RNA Vviral genomes. Annu. Rev. Phytopathol. 37, 151-174. doi: 10.1146/ annurev.phyto.37.1.151

Dreher, T. W. (2009). Role of tRNA-like structures in controlling plant virus replication. Virus Res. 139, 217-229. doi: 10.1016/j.virusres.2008.06.010

Haasnoot, P. C., Brederode, F. T., Olsthoorn, R. C., and Bol, J. F. (2000). A conserved hairpin structure in Alfamovirus and Bromovirus subgenomic promoters is required for efficient RNA synthesis in vitro. RNA 6, 708-716. doi: $10.1017 / \mathrm{S} 1355838200992471$

Han, S., and Sanfacon, H. (2003). Tomato ringspot virus proteins containing the nucleoside triphosphate binding domain are transmembrane proteins that associate with the endoplasmic reticulum and cofractionate with replication complexes. J. Virol. 77, 523-534. doi: 10.1128/JVI.77.1.523-534.2003

Houser-Scott, F., Ansel-Mckinney, P., Cai, J. M., and Gehrke, L. (1997). In vitro genetic selection analysis of Alfalfa mosaic virus coat protein binding to $3^{\prime}$ terminal AUGC repeats in the viral RNAs. J. Virol. 71, 2310-2319.

Houser-Scott, F., Baer, M. L., Liem, K. F. Jr., Cai, J. M., and Gehrke, L. (1994). Nucleotide sequence and structural determinants of specific binding of coat protein or coat protein peptides to the $3^{\prime}$ untranslated region of Alfalfa mosaic virus RNA 4. J. Virol. 68, 2194-2205.

Huang, C. Y., Huang, Y. L., Meng, M., Hsu, Y. H., and Tsai, C. H. (2001). Sequences at the $3^{\prime}$ untranslated region of Bamboo mosaic potexvirus RNA interact with the viral RNA-dependent RNA polymerase. J. Virol. 75, 2818-2824. doi: 10.1128/ JVI.75.6.2818-2824.2001

Iwakawa, H. O., Mizumoto, H., Nagano, H., Imoto, Y., Takigawa, K., Sarawaneeyaruk, S., et al. (2008). A viral noncoding RNA generated by cis-element-mediated protection against $5^{\prime}->3^{\prime}$ RNA decay represses both cap-independent and cap-dependent translation. J. Virol. 82, 10162-10174. doi: 10.1128/JVI.01027-08

Jiwan, S. D., and White, K. A. (2011). Subgenomic mRNA transcription in Tombusviridae. RNA Biol. 8, 287-294. doi: 10.4161/rna.8.2. 15195

Kao, C. C., and Sun, J. H. (1996). Initiation of minus-strand RNA synthesis by the Brome mosaic virus RNA-dependent RNA polymerase: use of oligoribonucleotide primers. J. Virol. 70, 6826-6830. 
Karpova, O. V., Zayakina, O. V., Arkhipenko, M. V., Sheval, E. V., Kiselyova, O. I., Poljakov, V. Y., et al. (2006). Potato virus X RNA-mediated assembly of singletailed ternary 'coat protein-RNA-movement protein' complexes. J. Gen. Virol. 87, 2731-2740. doi: 10.1099/vir.0.81993-0

Kawakami, S., Watanabe, Y., and Beachy, R. N. (2004). Tobacco mosaic virus infection spreads cell to cell as intact replication complexes. Proc. Natl. Acad. Sci. U.S.A. 101, 6291-6296. doi: 10.1073/pnas.0401 221101

Kim, K. H., and Hemenway, C. (1997). Mutations that alter a conserved element upstream of the Potato virus $X$ triple block and coat protein genes affect subgenomic RNA accumulation. Virology 232, 187-197. doi: 10.1006/viro.1997. 8565

Kim, K. H., and Hemenway, C. L. (1999). Long-distance RNA-RNA interactions and conserved sequence elements affect Potato virus $X$ plus-strand RNA accumulation. RNA 5, 636-645. doi: 10.1017/S1355838299982006

Kwon, S. J., Park, M. R., Kim, K. W., Plante, C. A., Hemenway, C. L., and Kim, K. H. (2005). cis-Acting sequences required for coat protein binding and in vitro assembly of Potato virus X. Virology 334, 83-97. doi: 10.1016/j.virol.2005. 01.018

Laliberte, J. F., and Sanfacon, H. (2010). Cellular remodeling during plant virus infection. Annu. Rev. Phytopathol. 48, 69-91. doi: 10.1146/annurev-phyto073009-114239

Lee, Y. S., Hsu, Y. H., and Lin, N. S. (2000). Generation of subgenomic RNA directed by a satellite RNA associated with Bamboo mosaic potexvirus: analyses of potexvirus subgenomic RNA promoter. J. Virol. 74, 10341-10348. doi: 10. 1128/JVI.74.22.10341-10348.2000

Lee, Y. S., Lin, B. Y., Hsu, Y. H., Chang, B. Y., and Lin, N. S. (1998). Subgenomic RNAs of Bamboo mosaic potexvirus-V isolate are packaged into virions. J. Gen. Virol. 79, 1825-1832. doi: 10.1099/0022-1317-79-7-1825

Lin, J. W., Chiu, H. N., Chen, I. H., Chen, T. C., Hsu, Y. H., and Tsai, C. H. (2005a). Structural and functional analysis of the cis-acting elements required for plus-strand RNA synthesis of Bamboo mosaic virus. J. Virol. 79, 9046-9053.

Lin, J. W., Ding, M. P., Hsu, Y. H., and Tsai, C. H. (2007). Chloroplast phosphoglycerate kinase, a gluconeogenetic enzyme, is required for efficient accumulation of Bamboo mosaic virus. Nucleic Acids Res. 35, 424-432. doi: 10.1093/nar/gkl1061

Lin, J. W., Hsu, Y. H., and Tsai, C. H. (2005b). Characterization of the infectivity of Bamboo mosaic virus with its correlation to the in vitro replicase activities in Nicotiana benthamiana. Virus Res. 112, 77-84.

Lin, N. S., Lin, F. Z., Huang, T. Y., and Hsu, Y. H. (1992). Genome properties of Bamboo mosaic virus. Phytopathology 82, 731-734. doi: 10.1094/Phyto-82-731

Lough, T. J., Lee, R. H., Emerson, S. J., Forster, R. L., and Lucas, W. J. (2006). Functional analysis of the $5^{\prime}$ untranslated region of potexvirus RNA reveals a role in viral replication and cell-to-cell movement. Virology 351, 455-465. doi: 10.1016/j.virol.2006.03.043

McCartney, A. W., Greenwood, J. S., Fabian, M. R., White, K. A., and Mullen, R. T. (2005). Localization of the Tomato bushy stunt virus replication protein p33 reveals a peroxisome-to-endoplasmic reticulum sorting pathway. Plant Cell 17, 3513-3531. doi: 10.1105/tpc.105.036350

McCormack, J. C., Yuan, X., Yingling, Y. G., Kasprzak, W., Zamora, R. E., Shapiro, B. A., et al. (2008). Structural domains within the $3^{\prime}$ untranslated region of Turnip crinkle virus. J. Virol. 82, 8706-8720. doi: 10.1128/JVI. 00416-08

Miller, W. A., Dreher, T. W., and Hall, T. C. (1985). Synthesis of Brome mosaic virus subgenomic RNA in vitro by internal initiation on (-)-sense genomic RNA. Nature 313, 68-70. doi: 10.1038/313068a0

Mochizuki, T., Hirai, K., Kanda, A., Ohnishi, J., Ohki, T., and Tsuda, S. (2009). Induction of necrosis via mitochondrial targeting of Melon necrotic spot virus replication protein p29 by its second transmembrane domain. Virology 390, 239-249. doi: 10.1016/j.virol.2009. 05.012

Nagy, P. D. (2016). Tombusvirus-host interactions: co-opted evolutionarily conserved host factors take center court. Annu. Rev. Virol. 3, 491-515. doi: 10.1146/annurev-virology-110615-042312

Newburn, L. R., and White, K. A. (2015). Cis-acting RNA elements in positivestrand RNA plant virus genomes. Virology 479-480, 434-443. doi: 10.1016/j. virol.2015.02.032
Nishikiori, M., Dohi, K., Mori, M., Meshi, T., Naito, S., and Ishikawa, M. (2006). Membrane-bound Tomato mosaic virus replication proteins participate in RNA synthesis and are associated with host proteins in a pattern distinct from those that are not membrane bound. J. Virol. 80, 8459-8468. doi: 10.1128/JVI. 00545-06

Osman, T. A., and Buck, K. W. (1996). Complete replication in vitro of Tobacco mosaic virus RNA by a template-dependent, membrane-bound RNA polymerase. J. Virol. 70, 6227-6234.

Osman, T. A., Olsthoorn, R. C., and Livieratos, I. C. (2014). Role of the Pepino mosaic virus $3^{\prime}$-untranslated region elements in negative-strand RNA synthesis in vitro. Virus Res. 190, 110-117. doi: 10.1016/j.virusres.2014. 06.018

Pasternak, A. O., Van Den Born, E., Spaan, W. J., and Snijder, E. J. (2001). Sequence requirements for RNA strand transfer during nidovirus discontinuous subgenomic RNA synthesis. EMBO J. 20, 7220-7228. doi: 10.1093/emboj/20. 24.7220

Petrova, E. K., Nikitin, N. A., Protopopova, A. D., Arkhipenko, M. V., Yaminsky, I. V., Karpova, O. V., et al. (2013). The role of the $5^{\prime}$-cap structure in viral ribonucleoproteins assembly from Potato virus $X$ coat protein and RNAs. Biochimie 95, 2415-2422. doi: 10.1016/j.biochi.2013. 09.004

Petrova, E. K., Nikitin, N. A., Trifonova, E. A., Protopopova, A. D., Karpova, O. V., and Atabekov, J. G. (2015). The 5'-proximal region of Potato virus $X$ RNA involves the potential cap-dependent "conformational element” for encapsidation. Biochimie 115, 116-119. doi: 10.1016/j.biochi.2015. 05.012

Prod'homme, D., Jakubiec, A., Tournier, V., Drugeon, G., and Jupin, I. (2003). Targeting of the Turnip yellow mosaic virus $66 \mathrm{~K}$ replication protein to the chloroplast envelope is mediated by the $140 \mathrm{~K}$ protein. J. Virol. 77, 9124-9135. doi: 10.1128/JVI.77.17.9124-9135.2003

Reusken, C. B., and Bol, J. F. (1996). Structural elements of the $3^{\prime}$-terminal coat protein binding site in Alfalfa mosaic virus RNAs. Nucleic Acids Res. 24, 2660-2665. doi: 10.1093/nar/24.14.2660

Rossmann, M. G. (2013). Structure of viruses: a short history. Q. Rev. Biophys. 46, 133-180. doi: 10.1017/S0033583513000012

Sawicki, S. G., and Sawicki, D. L. (1998). A new model for coronavirus transcription. Adv. Exp. Med. Biol. 440, 215-219. doi: 10.1007/978-1-46155331-1_26

Schaad, M. C., Jensen, P. E., and Carrington, J. C. (1997). Formation of plant RNA virus replication complexes on membranes: role of an endoplasmic reticulumtargeted viral protein. EMBO J. 16, 4049-4059. doi: 10.1093/emboj/16. 13.4049

Scholthof, K. B., Adkins, S., Czosnek, H., Palukaitis, P., Jacquot, E., Hohn, T., et al. (2011). Top 10 plant viruses in molecular plant pathology. Mol. Plant Pathol. 12, 938-954. doi: 10.1111/j.1364-3703.2011.00752.x

Singh, R. N., and Dreher, T. W. (1997). Turnip yellow mosaic virus RNA-dependent RNA polymerase: initiation of minus strand synthesis in vitro. Virology 233, 430-439. doi: 10.1006/viro.1997.8621

Song, C., and Simon, A. E. (1995). Requirement of a $3^{\prime}$-terminal stem-loop in in vitro transcription by an RNA-dependent RNA polymerase. J. Mol. Biol. 254, 6-14. doi: 10.1006/jmbi.1995.0594

Sun, X., and Simon, A. E. (2006). A cis-replication element functions in both orientations to enhance replication of Turnip crinkle virus. Virology 352, 39-51. doi: 10.1016/j.virol.2006.03.051

Sztuba-Solinska, J., Stollar, V., and Bujarski, J. J. (2011). Subgenomic messenger RNAs: mastering regulation of (+)-strand RNA virus life cycle. Virology 412, 245-255. doi: 10.1016/j.virol.2011.02.007

Tsai, C. H., Cheng, C. P., Peng, C. W., Lin, B. Y., Lin, N. S., and Hsu, Y. H. (1999). Sufficient length of a poly(A) tail for the formation of a potential pseudoknot is required for efficient replication of Bamboo mosaic potexvirus RNA. J. Virol. 73, 2703-2709.

Wei, T., Huang, T. S., Mcneil, J., Laliberte, J. F., Hong, J., Nelson, R. S., et al. (2010). Sequential recruitment of the endoplasmic reticulum and chloroplasts for plant potyvirus replication. J. Virol. 84, 799-809. doi: 10.1128/JVI. 01824-09

White, K. A. (2002). The premature termination model: a possible third mechanism for subgenomic mRNA transcription in (+)-strand RNA viruses. Virology 304, 147-154. doi: 10.1006/viro.2002.1732 
White, K. A., Bancroft, J. B., and Mackie, G. A. (1992). Mutagenesis of a hexanucleotide sequence conserved in potexvirus RNAs. Virology 189, 817-820. doi: 10.1016/0042-6822(92)90614-U

Conflict of Interest Statement: The authors declare that the research was conducted in the absence of any commercial or financial relationships that could be construed as a potential conflict of interest.
Copyright (c) 2017 Chen, Huang and Tsai. This is an open-access article distributed under the terms of the Creative Commons Attribution License (CC BY). The use, distribution or reproduction in other forums is permitted, provided the original author(s) or licensor are credited and that the original publication in this journal is cited, in accordance with accepted academic practice. No use, distribution or reproduction is permitted which does not comply with these terms. 